\title{
THE USE OF POLLS \\ TO ENHANCE FORMATIVE ASSESSMENT PROCESSES IN MATHEMATICS CLASSROOM DISCUSSIONS
}

\author{
Annalisa Cusi*, Francesca Morselli**, Cristina Sabena* \\ * University of Torino, Italy **University of Genova, Italy
}

This contribution addresses the theme of technology for formative assessment in the mathematics classroom. Taking a design-based research approach within the European project FaSMEd, we focus on the ways connected classroom technology may support formative assessment strategies in whole class activities. The theoretical background will be based on a three-dimensional model that relates the enactment of different formative assessment strategies by the various agents (teacher, peers, and the student) to different functionalities of technology. The study is based on design experiments, developed through the use of a connected classroom technology (IDM-TClass) through which students may share their productions, opinions and reflections with their classmates and the teacher during or at the end of a mathematical activity. Among other features, IDM-TClass enables the teacher to create polls, submit them to the students, gather their answers and show the results in real time. The paper discusses how polls can be used during classroom activities to foster the activation of formative assessment strategies. As a result of the design based research, we will present our classification of polls according to their contents and aims. Data analysis will be conducted on qualitative base and different ways of structuring classroom discussions and patterns of formative assessment strategies will be discussed.

Keywords: Connected classroom technologies, formative assessment, polls, classroom discussion.

\section{INTRODUCTION AND BACKGROUND}

This contribution stems from a designed-based research (DBRC 2003) carried out within the European project FaSMEd, which focuses on the ways technology may support formative assessment strategies in whole classroom activities.

Formative assessment (FA) or assessment for learning is conceived as a teaching method, where "evidence about student achievement is elicited, interpreted, and used by teachers, learners, or their peers, to make decisions about the next steps in instruction that are likely to be better, or better founded, than the decisions they would have taken in the absence of the evidence that was elicited" (Black \& Wiliam 2009, p. 7).

Research has highlighted the support given to FA by the so called connected classroom technologies (CCT), i.e. networked systems of computers or handheld devices specifically designed to be used in a classroom for interactive teaching and learning (Irving 2006). Specifically, research has underlined those affordances of CCT that make them effective tools for FA: monitoring students' progress, collecting the content of students' interaction over long timespans and over multiple sets of classroom participants (Roschelle \& Pea 2002); providing students with immediate private feedback, supporting them with appropriate remediation and keeping them oriented on the path to deep conceptual understanding (Irving 2006); enabling students to take a more active role in 
the classroom discussions and encouraging them to reflect and monitor their own progress (Roschelle \& Pea 2002, Ares 2008).

Our study investigates how CCT may be exploited to enhance FA during whole classroom activities (Cusi, Morselli \& Sabena 2017). In particular, in this contribution we focus on the possibility for the teacher of activating polls. Polls are a typical characteristic of what research calls Classroom Response Systems (CRS), which consist of a set of input devices for students, communicating with the software running on the instructor's computer, and enabling the instructor to pose questions to students and take a follow-up poll (Beatty \& Gerace 2009).

As Beatty and Gerace (ibid.) observe, CRS simultaneously provide anonymity and accountability, support collecting answers from all students in a class rather than just the few who speak up or are called upon, and enable recording data of students' individual and collective responses for subsequent analysis. These authors also highlight that CRS may be used by the teacher with great flexibility, and list specific instructional purposes connected to their use. Among them are the use of polls for:

- status check, that is to ask students their self-reported degree of confidence in their understanding of a topic;

- exit poll, that is to poll students to find out which concepts they want to spend more time on;

- assess prior knowledge, that is to elicit what students know or believe about a topic;

- provoke thinking, that is to ask a question to get students engaged within a new topic;

- elicit a misconception, that is to lead students to manifest a specific common misconception or belief that may hinder their learning;

- exercise a cognitive skill, that is to engage students in a specific cognitive activity;

- stimulate discussion with questions having multiple reasonable answers;

- review, that is to pose questions aimed at reminding students a body of material already covered.

Notwithstanding the potential of these tools, many researchers have stressed that their effectiveness depends on the skill of the instructor and on his/her ability to incorporate procedures such as tracking students' progress, keeping students motivated and enhancing reflection with technologies (Irving 2006). Other studies have highlighted that connected classroom technologies increased the complexity of the teacher's role with respect to 'orchestrating' the lesson (Clark-Wilson 2010, Roschelle \& Pea 2002). Therefore, in order to bring about progress in student participation and achievement, technology must be used in conjunction with particular kinds of teaching strategies.

Beatty and Gerace (2009) developed technology-enhanced formative assessment (TEFA), a pedagogical approach for teaching science and mathematics with the aid of classroom response systems. To help teachers implement FA, the TEFA approach introduces an iterative cycle of question posing, answering, and discussing, which forms a scaffold for structuring whole-class interaction. The essential phases of the cycle are:

- pose a challenging question to the students;

- have students wrestle with the question and decide upon a response;

- use a CRS to collect responses and display a chart of the aggregated responses;

- elicit different reasons and justifications from students for the chosen responses;

- develop a student-dominated discussion of the assumptions, perceptions, ideas and arguments involved;

- provide a summary, micro-lecture, meta-level comments. 
In our research, we exploited the use of polls to enhance effective classroom discussions with FA purposes. In this paper we will analyse, in particular, how the processing of students' answers carried out by connected classroom technology can be exploited to activate different FA strategies.

The study is part of a wider design-based research, characterized by cycles of design, enactment, analysis and redesign, where the goal of designing learning environments is intertwined with that of developing new theories (DBRC 2003). The research is carried out in authentic settings (classroom environments) focusing on "interactions that refine our understanding of the learning issues involved" (ibid., p. 5).

\section{FORMATIVE ASSESSMENT WITH TECHNOLOGY: A THEORETICAL FRAMEWORK}

Wiliam and Thompson (2007) identified five key strategies for FA:

(A) Clarifying and sharing learning intentions and criteria for success;

(B) Engineering effective classroom discussions and other learning tasks that elicit evidence of student understanding;

(C) Providing feedback that moves learners forward;

(D) Activating students as instructional resources for one another;

(E) Activating students as the owners of their own learning.

These strategies may be activated by three agents: the teacher, the peers and the student himself. Technology, indeed, may support the three agents in activating the FA strategies in different ways.

Within the FaSMEd project, we developed a three-dimensional framework for the design and implementation of technologically-enhanced formative assessment activities. The framework is represented in the chart ${ }^{1}$ in Figure 1 and extends Wiliam and Thompson's model, adding to it the dimension related to the functionalities through which technology could support FA (Aldon et al. 2017, Cusi, Morselli \& Sabena 2017). These functionalities are:

(1) Sending and displaying, that is the ways in which technology support the communication among the agents of FA processes (e.g. sending and receiving messages and files, displaying and sharing screens or documents to the whole class...).

(2) Processing and analysing, that is the ways in which technology supports the processing and the analysis of the data collected during the lessons (e.g. through the sharing of the statistics of students' answers to polls or questionnaires, the feedbacks given directly by the technology to the students when they are performing a test...).

(3) Providing an interactive environment, that is when technology enables to create environments in which students can interact to work individually or in groups on a task or to explore mathematical/ scientific contents (e.g. through the creation of interactive boards to be shared by teacher and students or the use of specific software that provides an environment where it is possible to dynamically explore specific mathematical problems...).

\footnotetext{
${ }^{1}$ We thank D. Wright (Newcastle University) for the digital version of the chart and Hana Ruchniewicz (University of Duisburg-Essen) for its adaptation.
} 


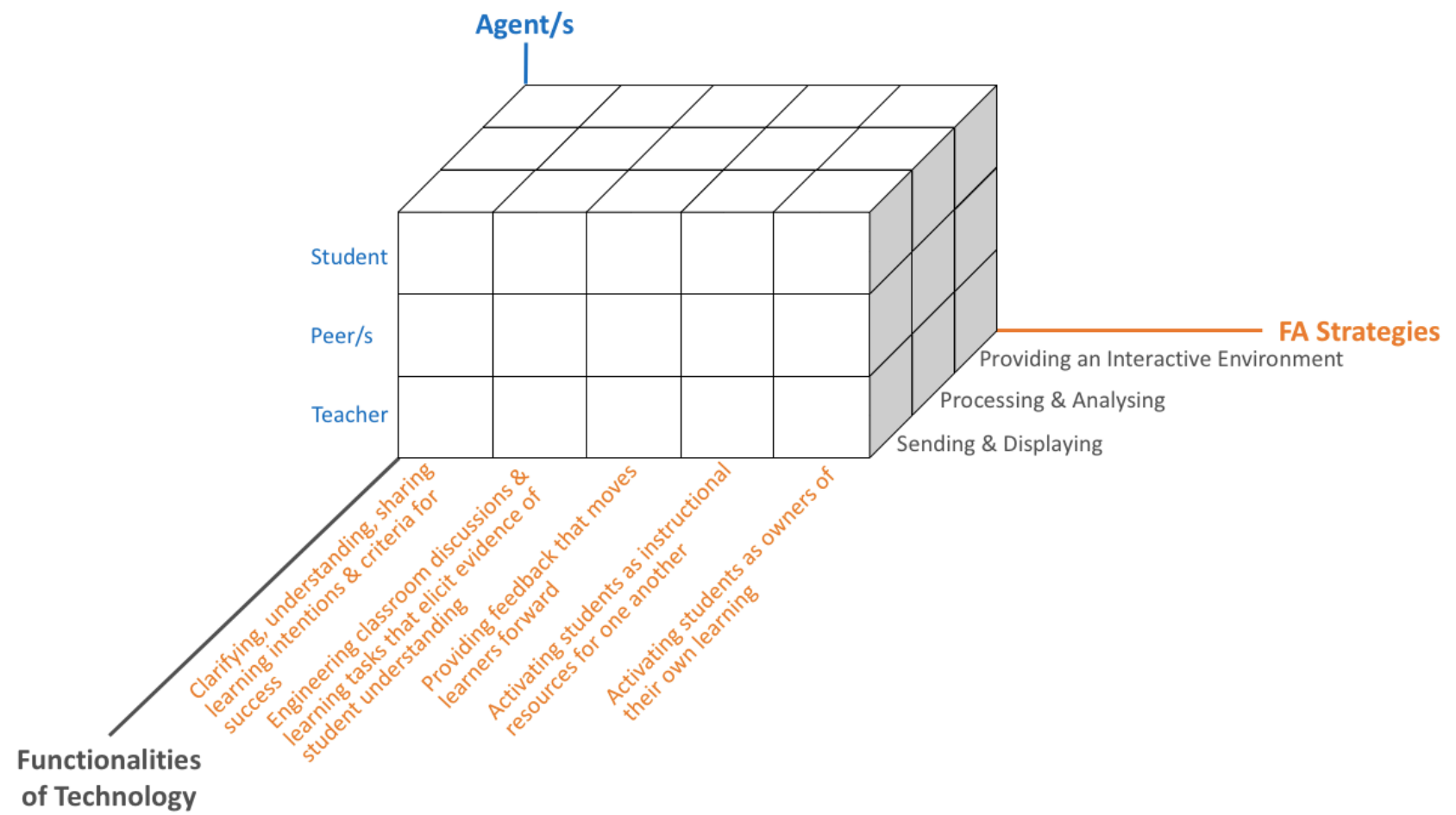

Fig. 1: Chart of the FaSMEd three-dimensional model

A fundamental aspect on which FA is focused is feedback, defined by Hattie and Timperley (2007) as "information provided by an agent (e.g. teacher, peer, book, parent, self, experience) regarding aspects of one's performance or understanding" (p.81).

In our design and in the data analysis we refer, in particular, to the four major levels of feedback introduced by Hattie and Timperley (ibid):

- feedback about the task, which concerns how well a task is being accomplished or performed;

- feedback about the processing of the task, which concerns the processes underlying tasks or relating and extending tasks;

feedback about self-regulation, which refers to the way students monitor, direct, and regulate actions toward the learning goal;

- feedback about the self as a person, which consists in positive (and sometimes negative) evaluations and affect about the student.

\section{DESIGNING FA ACTIVITIES WITHIN A CCT ENVIRONMENT}

In our design study, we adopt a Vygotskyan perspective on the crucial role of the interaction with peers and with an expert in students' learning (Vygotsky 1978). In this frame, we consider effective mathematical discussions (Bartolini Bussi 1998) as fundamental activities, where the teacher plays a key role in planning and promoting fruitful occasions for FA and learning.

Moreover, we believe that FA has to focus also on metacognitive factors (Schoenfeld 1992). Accordingly, we designed activities aimed at supporting students in (a) making their thinking visible (Collins, Brown \& Newmann 1989) through the sharing of their thinking processes with the 
teacher and the classmates by means of argumentative processes, and (b) developing their ongoing reflections on the learning processes.

An important feature of the task design is a strong argumentative component: students are always required explain their answers in a written text. Students' argumentations are then collectively analysed according to three criteria: the correctness (Do these justifications contain any mistake?), the clearness (Is every reader able to easily understand these justifications?) and the completeness (Do these justifications contain all the information necessary to draw these conclusions?) of the justifications provided by the students.

Concerning technology, we explored the use of a CCT (provided by a software called IDMTClass), which connects the students' tablets with the teacher's laptop, allows the students to share their productions and the teacher to easily collect the students' opinions and reflections, during or at the end of an activity, by means of the creation of instant polls.

The use of IDM-TClass was integrated within a set of activities on relations and functions as well as their representations (symbolic representations, tables, graphs) adapted from different sources (the ArAl Project: www.progettoaral.it; and the Mathematics Assessment Program: http://map.mathshell.org). For each activity, we designed a sequence of worksheets, to be sent to the students' tablets or to be displayed on the interactive whiteboard (or through the data projector).

The worksheets were designed according to three main categories: (1) worksheets introducing a problem and asking one or more questions (problem worksheets), (2) worksheets aimed at providing support to students who meet difficulties in facing the given tasks (helping worksheets), and (3) worksheets prompting a poll between proposed options (poll worksheets).

Concerning the poll modality, IDM-TClass software collects all the students' choices and processes them, displaying an analytical record (collection of each answer) as well as a synthetic overview (bar chart). In reference to the analytical framework, instant polls are used through the support of the "Processing and Analysing" functionality of the technology. The possibility of showing the results in real time brings to the fore also the "Sending and Displaying" functionality of technology.

In principle, the software enables also to set the time given to students before completing the poll, and offers the opportunity to provide an immediate automatic correction to the student. However, our choice is not to provide the immediate automatic correction to students, so that they could be engaged in a subsequent classroom discussion. In tune with Beatty and Gerace (2009) framework, in fact, we conceive the use of polls as a way of scaffolding whole-class interaction with the aim of fostering the sharing of results and the comparison between students (FA strategy $B$ ). This is also coherent with our belief on the key role of the teacher and the importance of peer interaction.

During the design experiments, we implemented planned polls and instant polls. Planned polls were created a priori and were part of each teaching sequence. They were realized through poll worksheets, which can be used in alternative to problem worksheets Instant polls were on the contrary created and implemented on the spot during the lesson. In the perspective of design-based research, instant polls that reveal fruitful in terms of FA strategies may be inserted in the repertoire of planned polls for the subsequent cycles of experimentation.

\section{CATEGORIES OF POLLS}

In our design, polls are always intended as a starting point for a class discussion and not for individual "revising" or "status check". After three cycles of design, implementation and analysis of the classroom activities, we classified polls according to the different focus and aims of the classroom discussions developed starting from them. 
We identified four categories of polls, which are presented in the following table, together with the corresponding aim and an example from our design experiments. Two examples will be presented in an extended way in the data analysis section.

\begin{tabular}{|c|c|c|}
\hline Category of poll & Corresponding aims & $\begin{array}{c}\text { Example from our design } \\
\text { experiments }\end{array}$ \\
\hline $\begin{array}{l}\text { 1) Polls on specific mathematical } \\
\text { content: these polls ask to choose } \\
\text { the correct answer to a problem } \\
\text { or to a specific question. }\end{array}$ & $\begin{array}{l}\text { - To highlight students' } \\
\text { understanding of specific topics } \\
\text { developed during the lesson. } \\
\text { - To make students discuss on the } \\
\text { reasons subtended to the choice of } \\
\text { the correct answers (providing } \\
\text { feedback about the task). } \\
\text { - To promote a discussion on the } \\
\text { solving strategies, in order to } \\
\text { enable students to share and } \\
\text { compare them (providing feedback } \\
\text { about the processing of the task). }\end{array}$ & $\begin{array}{l}\text { Every morning Tommaso walks a } \\
\text { straight road from his home to a } \\
\text { bus stop, a distance of } 160 \\
\text { meters. The graph shows his } \\
\text { journey on one particular day. } \\
\text { After how many seconds does } \\
\text { Tommaso reach the bus stop? } \\
\text { (a) After } 120 \text { seconds } \\
\text { (b) After } 50+70+100+120 \\
\text { seconds, that is after } 340 \text { seconds } \\
\text { (c) After } 100 \text { seconds } \\
\text { (d) After } 50 \text { seconds }\end{array}$ \\
\hline $\begin{array}{l}\text { 2) Polls on argumentation: these } \\
\text { polls ask to compare different } \\
\text { justifications about the answers } \\
\text { to a given problem. }\end{array}$ & $\begin{array}{l}\text { - To promote a discussion at a } \\
\text { meta-mathematical level, focused } \\
\text { on the way the answer is justified. } \\
\text { Thanks to this kind of discussion, } \\
\text { students are led to identify the } \\
\text { criteria to assess the answers. } \\
\text { Hence, students receive and } \\
\text { provide feedback on the } \\
\text { processing of the task and } \\
\text { feedback about self-regulation. }\end{array}$ & See the paragraph "Example 1". \\
\hline $\begin{array}{l}\text { 3) Polls on metacognitive } \\
\text { aspects: these polls are focused } \\
\text { on the difficulties students meet } \\
\text { when facing specific kind of } \\
\text { tasks or on the best strategies to } \\
\text { be used to face specific tasks. }\end{array}$ & $\begin{array}{l}\text { - To promote metacognitive } \\
\text { reflections that could help students } \\
\text { in identifying the available tools } \\
\text { to face similar tasks in the future } \\
\text { and in becoming aware of how to } \\
\text { monitor themselves while facing } \\
\text { this kind of tasks (providing }\end{array}$ & See the paragraph "Example 2". \\
\hline
\end{tabular}




\begin{tabular}{|l|l|l|}
\hline & feedback about self-regulation). & \\
\hline $\begin{array}{l}\text { 4) Polls on affective aspects: } \\
\text { these polls are focused on } \\
\text { students' feelings when facing a } \\
\text { specific kind of task or when a } \\
\text { particular methodology is } \\
\text { adopted during the lessons. }\end{array}$ & $\begin{array}{l}\text { - To bring to the fore the affective } \\
\text { dimension, supporting students in } \\
\text { becoming aware on their way of } \\
\text { posing themselves during this } \\
\text { kind of activities (providing } \\
\text { feedback about self-regulation). }\end{array}$ & $\begin{array}{l}\text { How did you feel when your } \\
\text { answer was displayed on the } \\
\text { interactive whiteboard? } \\
\text { A) Happy } \\
\text { C) Calm } \\
\text { D) Worried }\end{array}$ \\
\hline
\end{tabular}

Table 1: Categories of polls resulting from our design experiments

Referring to the instructional purposes of polls described by Beatty and Gerace's framework (2009), polls belonging to category 1 may be related to "provoke thinking" and "exercise a cognitive skill", whereas the polls belonging to category 2 may be linked to "elicit a misconception" and "stimulate discussion with questions having multiple reasonable answers". Polls belonging to categories 3 and 4 are of different nature; even if they could be somehow related to "status check", they bring to the fore metacognitive and affective issues that are not so evident in Beatty and Gerace's list.

\section{RESEARCH QUESTIONS AND METHODOLOGY}

Concerning polls, our investigation is guided by the following research questions:

- Which FA strategies can be activated thanks to the use of technology enhanced polls?

- What are the main characteristics of the FA discussions developed thanks to the activation of polls? i.e.: How could they be initiated? How could they evolve?

All the lessons were video-recorded, fields notes were taken, and students' productions (doc files) were collected, building a large amount of data (about 450 hours of class sessions, carried out in collaboration with 20 teachers).

In line with design-based research, the study is carried out through a close collaboration between researchers and teachers, who share the aim of improving practice, taking into account both contextual constraints and research aims.

At least one researcher was always present in the classroom as participant observer during the design experiments.

The analysis of the video-recordings of class discussion was developed according to the following methodology:

- a preliminary selection of class sessions was made on the basis of researchers' direct observations;

- the selected classroom discussion episodes were transcribed and analysed separately by the researchers, who coded the transcripts in terms of FA strategies;

- problematic codes were discussed together so that researchers could come to agreement. 


\section{DATA ANALYSIS}

Hereunder we present two examples taken from our experiments. Both examples refer to a task sequence on time-distance graphs adapted from the task sequence "Interpreting time-distance graphs", from the Mathematics Assessment Program (http://map.mathshell.org/materials/lessons.php). From the original source based on paper-andpencil materials for grade 8 , we adapted the activities and created a set of 19 digital worksheets to be used with students from grade 5 to 7 (age 10-12).

The sequence starts with a short text about the walk of a student, Tommaso, from home to the bus stop. This text is accompanied by a time-distance graph, as illustrated in Figure 2:

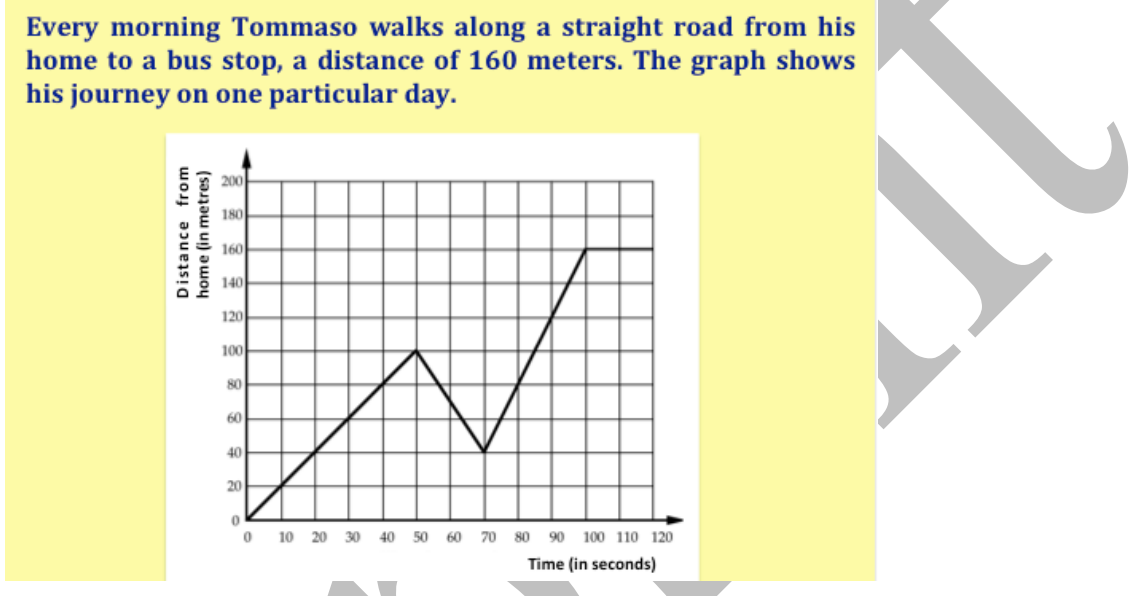

Fig.2: The time-distance graph of Tommaso's walk

Students' interpretation of this graph is guided through questions, posed to them within problem, helping, and poll worksheets. After the interpretation of the given time-distance graph according to the given story, the activity develops through the matching between different graphs and the corresponding stories and the construction of graphs associated to specific stories. Since the students were at their first encounter with time-distance graphs, we designed an introductory activity based on the use of a motion sensor, in which students could explore in a laboratorial way the construction of the graph after a motion experience along a straight line.

\section{EXAMPLE 1: A CLASSROOM DISCUSSION FROM A POLL ON ARGUMENTATION}

In the following, we present an excerpt from a grade 7 class discussion starting from a poll belonging to category 2: Polls that ask to compare different answers to a problem. The episode concerns the interpretation of the final part of the graph in figure 2. At first, students were asked via a problem worksheet to establish what happens during the last 20 seconds, and to justify their answers. During the classroom discussion, a poll worksheet was used to focus on the completeness of answers, which may be referred to FA strategy A (Clarifying and sharing learning intentions and criteria for success). Specifically, the poll required students to identify which is the most complete among three given answers:

"Some students of another class wrote these answers. Which of them is the most complete?

A) During the last 20s, Tommaso is not walking because we have already said that he has reached the bus stop.

B) I think that, during the last 20s, Tommaso is not walking because from the graph it is possible to understand that, in the period between 100s and 120s, he is always at the same distance from home, that is $160 \mathrm{~m}$. 
Option B represents the most complete answer to the question about what happens to Tommaso during the last 20 seconds because it refers to the correct interpretation of the graph in terms of time and corresponding distance from home. Option A is the typical justification provided by a student who is not referring to the graph, but only to his knowledge about "the end of the story" (Tommaso reaches the bus stop). Option $\mathrm{C}$ could be the typical answer of those students who prefer to refer to their previous experience with the motion sensor (through which they discovered that a horizontal line represents the fact that an object is not moving), instead of trying to understand how this conclusion could be drawn through a deeper interpretation of the graph.

In order to answer to the poll, students discussed in pairs. After all the pairs sent their answers, the teacher displayed the distribution of answers on the IWB: $10 \%$ of the students chose option A, 50\% chose option B and $40 \%$ chose option C. Starting from the display of the results, the discussion took place. The teacher exploited the poll worksheet as a way to engineer effective classroom discussions that elicit evidence of student understanding (FA strategy B). Table 2 presents selected excerpts from the discussion, analysed according to the FaSMEd framework.

\begin{tabular}{|c|c|}
\hline Excerpts from the class discussion & $\begin{array}{l}\text { Analysis according to the FaSMEd three- } \\
\text { dimensional framework }\end{array}$ \\
\hline $\begin{array}{l}\text { After a brief analysis of A, justifications B } \\
\text { and C are compared. } \\
\text { 353) Teacher: let's look at B and C. Let's } \\
\text { hear some explanations of those who chose } \\
\text { C, why did they chose C, and some } \\
\text { motivations of those who chose B. } \\
\text { 354) Brown: we chose B because B } \\
\text { specifies also that he (Tommaso) stayed still } \\
\text { from } 100 \text { to } 120 \text { seconds, while C doesn't } \\
\text { say this, saying that they were only } 20 \\
\text { seconds they could have been } 150,170,180 \\
\text { and so on... } \\
\text { 355) Silvia: B is the most complete. } \\
\text { 356) Teacher: B is the most complete. } \\
\text { 357) Mario: for me B is not right because, } \\
\text { we understood that, when we used the } \\
\text { motion sensor, let's say, you understand that } \\
\text { a person stops when the line is horizontal, } \\
\text { and there (justification B) it doesn't say this, } \\
\text { then it is not the most complete. }\end{array}$ & $\begin{array}{l}\text { The teacher encourages the students to discuss } \\
\text { the reasons behind the choices of the poll. Her } \\
\text { aim is to promote a discussion on the } \\
\text { completeness of the two options. This is an } \\
\text { instance of } F A \text { Strategy } A \text {, since the focus is on } \\
\text { the requirements that a complete answer must } \\
\text { satisfy. } \\
\text { Suggesting that answer B gives more } \\
\text { information on the last trait, Brown activates } \\
\text { herself as responsible of her learning (FA } \\
\text { strategy } E \text { ) and at the same time as instructional } \\
\text { resource for her mates ( } F A \text { strategy } D \text { ). Silvia, } \\
\text { echoing Brown, affirms that B is the most } \\
\text { complete, thus giving an implicit feedback to } \\
\text { Brown ( } F A \text { strategy } C \text { ). In line } 357 \text { Mario } \\
\text { challenges the former evaluation, activating } \\
\text { himself as owner of his own learning ( } F A \\
\text { strategy } E \text { ): in his opinion, answer B is not } \\
\text { complete because it does not refer to the } \\
\text { experience with sensor detectors. This } \\
\text { intervention provides a good occasion to discuss } \\
\text { again the role and value of the empirical } \\
\text { experience with sensors. }\end{array}$ \\
\hline $\begin{array}{l}\text { 390) Lollo: but if we had not done that } \\
\text { activity before... }\end{array}$ & $\begin{array}{l}\text { Lollo suggests that one cannot refer to the } \\
\text { experience with sensors, since the answer should } \\
\text { be intelligible also by a reader who did not do } \\
\text { such an experience. Lollo turns himself as an }\end{array}$ \\
\hline
\end{tabular}




\begin{tabular}{|c|c|}
\hline $\begin{array}{l}\text { 391) Teacher: the activity with the motion } \\
\text { sensor. } \\
\text { 392) Lollo: we could not have known that if } \\
\text { you are still the line is horizontal. }\end{array}$ & $\begin{array}{l}\text { instructional resource for his mates (FA strategy } \\
D) \text {. In particular, he gives feedback to Mario } \\
(F A \text { strategy C). The teacher reformulates } \\
\text { Lollo's intervention so as to involve the other } \\
\text { students, turning Lollo as a resource for his } \\
\text { mates (FA strategy } D) \text {. In this way, she also } \\
\text { activates } F A \text { Strategy } C \text {. }\end{array}$ \\
\hline $\begin{array}{l}\text { 399) Rob: And, anyway, from the graph you } \\
\text { can understand why the distance is always } \\
\text { the same but the seconds, let's say, go on... } \\
\text { 400) Teacher: ok... then, even if we had not } \\
\text { had the experience with the motion sensor, } \\
\text { that made you understand in an } \\
\text { experimental way that if I stay still the line } \\
\text { is horizontal, your classmate [Rob] says: } \\
\text { "from the graph I can understand it } \\
\text { anyway". Why? Rob, could you please } \\
\text { repeat it? } \\
\text { 401) Rob: because from the graph you can } \\
\text { understand that when you don't move, that } \\
\text { is to say when there is the horizontal line... } \\
\text { 402) Teacher: what does it mean? } \\
\text { 403) Rob: the meters remain the same but } \\
\text { the seconds go on, let's say. }\end{array}$ & $\begin{array}{l}\text { Rob intervenes, stating that in the horizontal } \\
\text { trait the distance from home is always the same. } \\
\text { This is a shift from an explanation based on the } \\
\text { experience with sensors to a theoretical } \\
\text { explanation, based on the meaning of the graph. } \\
\text { Rob provides to other students a feedback to } \\
\text { move forward (FA strategy C), turning himself } \\
\text { as an instructional resource for his classmates } \\
(F A \text { strategy D). } \\
\text { The teacher reformulates Rob's intervention, } \\
\text { giving to all the students a feedback that moves } \\
\text { them forward (FA strategy } C) \text {. Reformulation is } \\
\text { also a means to activate Rob as a resource for } \\
\text { his classmates }(F A \text { strategy } D) \text {. }\end{array}$ \\
\hline $\begin{array}{l}\text { 413) Teacher: B explains why the line is } \\
\text { horizontal, while C just says "the line is } \\
\text { horizontal"; B instead explains why the line } \\
\text { is horizontal, because the meters remain the } \\
\text { same, even if time goes on, isn't it? }\end{array}$ & $\begin{array}{l}\text { As a final intervention, the teacher rephrases the } \\
\text { result of the discussion, pointing out what makes } \\
\text { answer B more complete. In this way, she } \\
\text { activates } F A \text { strategy } A \text {. }\end{array}$ \\
\hline
\end{tabular}

Table 2: Excerpts from the class discussion and corresponding analysis

\section{EXAMPLE 2: A DISCUSSION FROM A POLL ON METACOGNITIVE ASPECTS}

In the following, we present an excerpt from a grade 5 class discussion starting from a poll belonging to category 3: Polls on metacognitive aspects. The discussion developed starting from the results of an instant poll. The instant poll was proposed at the end of the task sequence on timedistance graphs. It was created on the spot by the teacher $(\mathrm{T})$ and researcher $(\mathrm{R})$ with the aim of boosting a metacognitive reflection on effective ways to tackle graph interpretation tasks. Here is the wording of the poll:

"When interpreting a graph, what is the first thing you look at?"

a) If the graph starts from the origin

b) If the graph goes up or down

c) If the graph has horizontal traits 

d) How many traits compose the graph
e) How steep is the graph
f) What is written on the axes.

We may note that, differently from the poll in example 1 , this poll does not encompass only one correct answer. The subsequent discussion is aimed at making visible students' strategies when approaching a graph and compare the efficiency of such strategies.

Most students (72\%) chose F ("What is written on the axes"); $18 \%$ chose A ("If the graph starts from the origin") and $9 \%$ chose C ("If the graph has horizontal traits") (see figure 3 for the representation of the results that was displayed to the class).

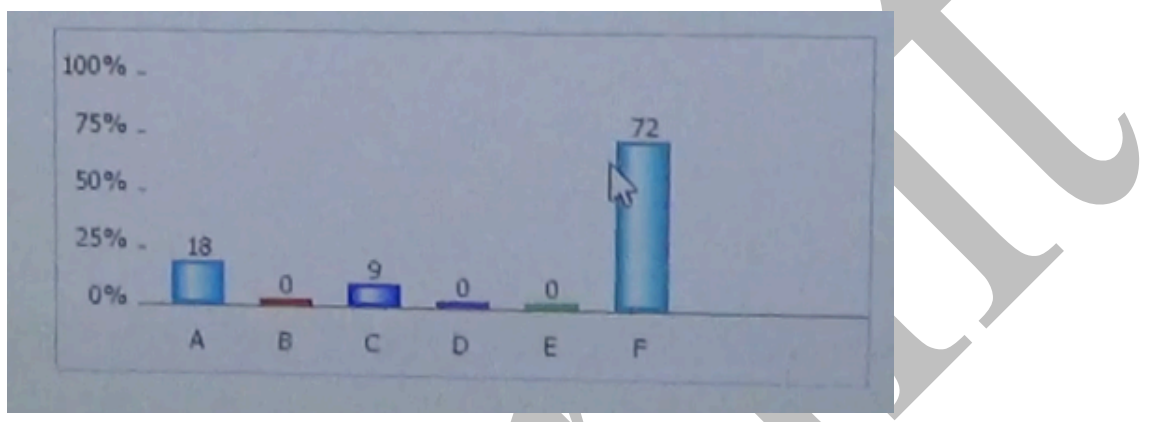

Fig. 3: Results of the instant poll, as displayed on the IWB.

Starting from the display of the results, the discussion took place. The teacher exploited the poll as a way to engineer effective classroom discussions that elicit evidence of student understanding ( $F A$ strategy $B$ ). Table 3 presents selected excerpts from the discussion, analysed according to the FaSMEd framework.

\begin{tabular}{|c|c|}
\hline Excerpts from the class & $\begin{array}{l}\text { cording to the FaSMEd three- } \\
\text { mensional framework }\end{array}$ \\
\hline $\begin{array}{l}\text { 1. Researcher: Here we haye } 72 \% \text { that } \\
\text { answered F. } \\
\text { 2. Teacher: that is the axes. } \\
\text { 3. Researcher: "What is written on the axes". } \\
\text { Someone chose A: "If the graph starts from } \\
\text { the origin". Someone chose C: "If there are } \\
\text { horizontal traits". The other options were not } \\
\text { chosen. Some of you said to have changed } \\
\text { her mind. Would you like to tell it now? } \\
\text { (speaking to Sabrina) } \\
\text { 4. Sabrina: We chose A, but later we changed } \\
\text { our mind. We want to choose F. } \\
\text { 5. Researcher: So, actually for you it is F? }\end{array}$ & $\begin{array}{l}\text { The functionality of technology is processing } \\
\text { and analysing, since the display of data is the } \\
\text { starting point for a discussion. The activated } \\
\text { FA strategy is B (engineering effective } \\
\text { classroom discussions). } \\
\text { Immediately after the display of the results, } \\
\text { Sabrina and her mate ask to change their } \\
\text { choice: this can mean that they recognize to } \\
\text { have answered without a deep reflection. } \\
\text { Recognizing this and asking to amend the } \\
\text { answer is an instance of FA strategy E (they } \\
\text { turn themselves as responsible of their own } \\
\text { learning). }\end{array}$ \\
\hline $\begin{array}{l}\text { 6. Researcher: We could start from F. Why do } \\
\text { you think the first thing to look at is what is } \\
\text { written on the axes? } \\
\text { Some students raise their hands. }\end{array}$ & $\begin{array}{l}\text { The initiation of the discussion consists in } \\
\text { focusing on the most chosen answer (we } \\
\text { remind that in this case there is not only one } \\
\text { correct answer). The teacher and the } \\
\text { researcher choose to focus on answer F also }\end{array}$ \\
\hline
\end{tabular}


8. Elsa: Because, if you look at what is written on the axes, you can already understand the graph... and you can get some information.

9. Researcher: Let's listen to somebody else. Carlo.

10. Carlo (he worked in pair with Elsa): I wanted to say that on the axes it is written what they are, what you have to measure, look at, observe...

11. Researcher: Ok.

12. Luca: Also on the axes... of, for instance, it had been the contrary, here (with gestures, he draws a vertical line) the time and here (with gestures, he draws a horizontal line) the distance, the graph would have changed... (he draws with gestures a possible new graph).

13. Researcher: Did you listen to what Luca said? (she is speaking with the other students)

14. Voices: Yes!

15. Researcher: I guess that somebody did not listen.

16. Teacher: He said a very interesting thing.

15. Researcher: Would you like to repeat what Luca said? (to Lavinia, who raised her hand).

16. Lavinia: We always have the distance from home (with gestures, she draws a vertical line) and time (with gestures, she draws a horizontal line), but maybe, in order to mislead us...

17. Teacher: Or because it is represented in another way. It could be! Then, it could be written...

18. Lavinia: In another way (with gestures, she draws the vertical and horizontal axes).

19. Researcher: Yes, that time is on the vertical axis and distance on the horizontal one. Luca said that, in that case, the graph changes. Or the same graph is interpreted in a different way. If I had a blackboard... I was thinking of the impossible graph (in facing one of the preceding problem worksheets of the sequence, the class had worked on an because it is undoubtedly important and efficient to start the work on a graph with the analysis of the axis.

Elsa and Carlo explain to their classmates that, by knowing which variables are represented on the axes, one can get many information on what is represented in the graph. Elsa and Carlo turn themselves as resources for their classmates (FA strategy D).

Luca points out that inverting the two variables represented on the axes leads to different graphs.

The researcher, in order to highlight Luca's intervention and to turn Luca into a real resource for the classmates (FA strategy $D$ ), carries out the following strategy: she asks if the other pupils listened to what Luca said, and asks another pupil to repeat it. This strategy makes Luca's thinking visible to the classmates.

Lavinia tries to repeat Luca's idea, activating herself as responsible of her learning (strategy $E$ ), but she speaks of "misleading" rather than of a different graph.

The teacher interrupts Lavinia and clarifies that there could be other possible graphs characterised by different variables represented on the two axes.

The researcher recalls to the students an impossible graph that was encountered in a previous problem worksheet. Her intervention is aimed at promoting a collective reflection on the fact that, if the variables change, the graph must be interpreted in another way.

We highlight the crucial choice of recalling a previous experience, occurred during the task 
impossible graph: time was represented on the horizontal axis, distance was represented on the vertical axis and the graph contained a vertical trait). Let's draw it...

23. Researcher: Ok. Now I draw only the vertical trait. If the time is here and the distance is here (she draws at the blackboard, see figure 4). We said that a vertical trait is impossible, isn't it?

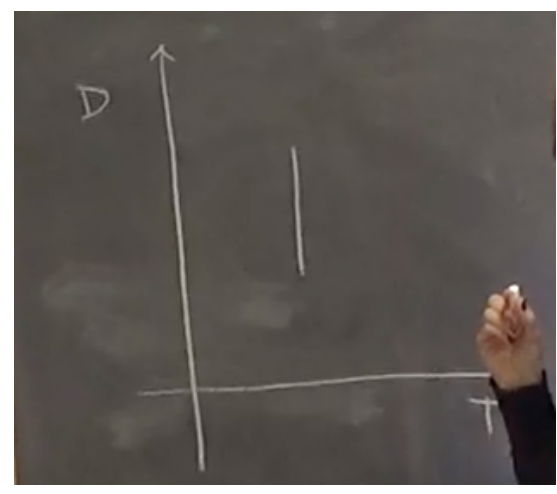

Figure 4: The first graph drawn at the blackboard

24. Voices: Yes.

25. Researcher: And if, instead, I put the time on the vertical axis, as Luca said, and the distance on the horizontal axis, would it be impossible? (she exchanges the variables on the axis in the same graph on the blackboard - see figure 5)

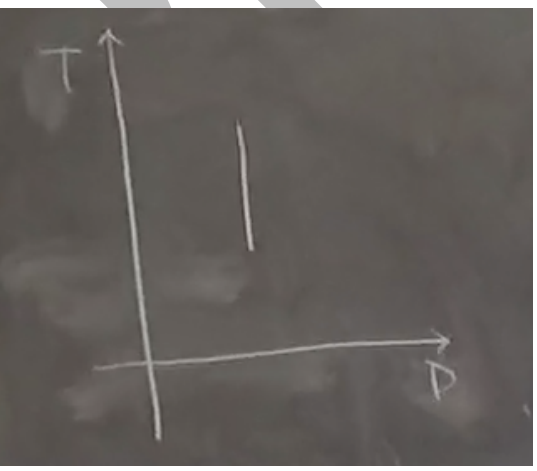

Figure 5: The new graph on the blackboard 26. Voices: No!

27. Student: It is possible! sequence. In this way, the researcher and the teacher may also collect some feedback about the previous activities (strategy $C$ ).

28. Researcher: How would it be? 
Many students raise their hands.

29. Researcher: Livio.

30. Livio: In my opinion, it is impossible, because he does not move... because... if... (he points to the drawing at the blackboard).

31. Teacher: You can come at the blackboard. Livio goes at the blackboard.

32. Livio: If this is time (he points to the vertical axis), he spends this amount of time (he points to the vertical trait of the graph, figure 6), but he remains still, (he points to the horizontal axis, figure 7) in this trait of time (he points again to the vertical trait, figure 8). afterwards he formulates a new interpretation.

Answering to the teacher and going to the blackboard, expressing his ideas, Livio acts as responsible of his own learning (FA strategy $E)$ and finally turns himself in a resource for his classmates (FA strategy $D)$.

We point out that Livio had not chosen option $\mathrm{F}$ in answering the poll. This means that the discussion enabled him to focus his attention on new specific aspects.

The new question posed by the researcher (concerning the new graph at the blackboard) makes him reflect on the importance of analysing the variables on the axes, and understand that the change of variables causes a change in the interpretation of the graph.

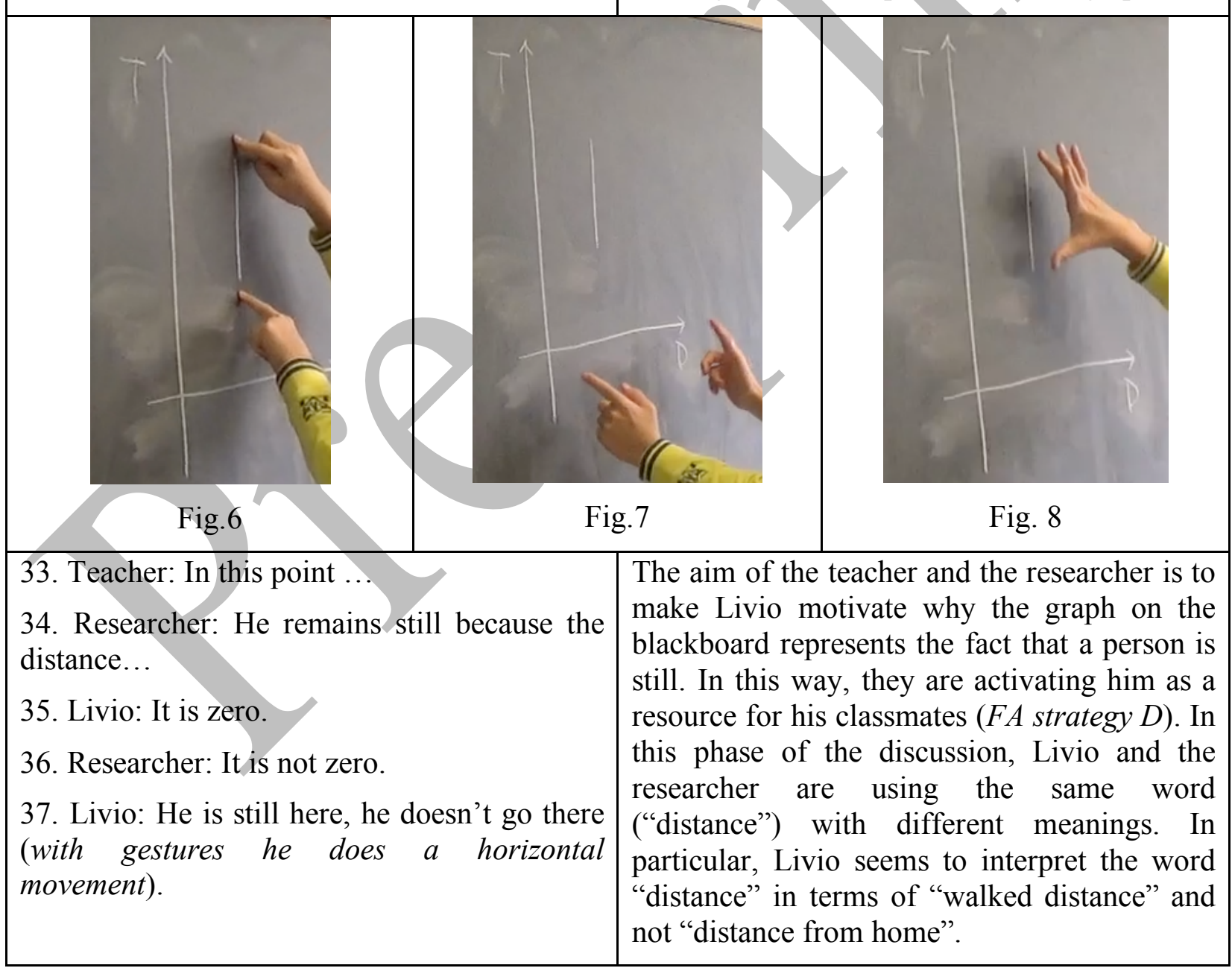




\begin{tabular}{|l|l|}
\hline $\begin{array}{l}\text { 38. Researcher: Let's listen to someone else. } \\
\text { 39. Teacher: Who agrees with him? Or on the } \\
\text { contrary: who doesn't agree? }\end{array}$ & $\begin{array}{l}\text { Carlo activates himself as a resource for Livio } \\
\text { and his classmates (FA strategy D), proposing } \\
\text { a correct interpretation of the word "distance" } \\
\text { (in term of "distance from home") and } \\
\text { 40. Researcher: Does somebody want to add } \\
\text { something to what Livio said? } \\
\text { trying the meaning of what Livio was } \\
\begin{array}{l}\text { trye students say no. Carlo raises his hand. } \\
\text { spends some time still, at a given distance } \\
\text { from home. }\end{array}\end{array}$ \\
$\begin{array}{l}\text { 42. Researcher: You wanted to add this. This } \\
\text { idea is very interesting. We must not think that } \\
\text { on the horizontal axis there is always the time } \\
\text { and on the vertical axis the distance, we must } \\
\text { be careful and check these aspects! }\end{array}$ & $\begin{array}{l}\text { Finally, the researcher gives a feedback that } \\
\text { moves the learners forward (FA strategy } C), \\
\text { since she highlights the need to analyse } \\
\text { carefully the variables represented on the axes } \\
\text { as an efficient starting strategy for all } \\
\text { activities involving the interpretation of } \\
\text { graphs. }\end{array}$ \\
\hline
\end{tabular}

Table 3: Excerpts from the class discussion and corresponding analysis

\section{DISCUSSION AND CONCLUSIONS}

In this chapter, we adopted a design based approach and we studied the use of polls for promoting formative assessment in mathematical lessons through the "Processing and Analysing" and "Sending and Displaying" functionalities of the technology. We presented a classification of polls into four categories in relation to their content and their didactical aims and we illustrated two categories by means of the analysis, performed thorough the FaSMEd analytical framework, of two episodes from our design experiments.

The episodes analysed in examples 1 and 2 resonate with the main phases of the TEFA cycle proposed by Beatty and Gerace (2009): pose a challenging question; have students wrestle with the question and decide upon a response; use a CRS to collect responses and display a chart; elicit different reasons and justifications from students; develop a student-dominated discussion; provide meta-level comments.

The analysis shows that the "Processing and Analysing" and "Sending and Displaying" functionalities of technology are efficient tools in enabling the teacher to share the results of polls with students and to structure around them a class discussion with FA purposes. In these discussions, a complex variety of FA strategies emerged with the involvement of all the classroom actors (students, peers and teacher). Moreover, the overall data analysis (based on about 450 hours of video-recording) allowed us also to highlight different structures of classroom discussions (and corresponding patterns of activated FA strategies) developed starting from polls. In the following we will present the main structures we identified, referring also to the two examples analysed in this paper.

First of all, we can distinguish between two main ways of initiating classroom discussions according to the percentages of students' answers in the case of polls with only one correct answer (categories 1 and 2). 
When percentages of the correct answer and of one or more incorrect ones are quite balanced, the discussion initiates asking students to compare these two (or more) options and to express the motivation subtended to their choice. In this way, it is possible to focus on the mistakes that could lead to the choice of incorrect answers and to make students activate themselves as owners of their own learning ( $F A$ strategy $E$ ). This is the case shown in example 1, which refers to a poll on argumentation in which the percentage of answers B (the correct one) is 50\% and the percentage of answer $\mathrm{C}$ (incorrect) is 40\%: as we can see from the excerpt, during the discussion the students could recognize their own mistakes and reflect on the reasons subtended to them. Also students who chose the correct answer could benefit from the discussion, because they are asked to make explicit their justification, hence, they could develop their awareness about the reasons why they chose a specific option (again activation of $F A$ strategy $E$ ). Furthermore, throughout the discussion, students are activated as instructional resources for their classmates (FA strategy $D$ ) because they give feedback to each other $(F A$ strategy $C$ ) on the reasons why a chosen option is better than the other.

When the percentages of students' answers are not balanced, the initiation of the discussion on the poll is different. After displaying the results of the poll, the teacher usually starts the discussion asking those, who chose the incorrect answer, to explain their choice (phase 1). This strategy results fruitful because it allows the students to focus on the mistakes subtended to the choice of incorrect answers, making them activate themselves as owners of their own learning ( $F A$ strategy $E)$. In this way, students can receive a feedback about the task (FA strategy $C$ ) and are, thus, supported in recognizing their own mistakes and reflecting on the reasons subtended to them.

Afterwards, the teacher asks those, who chose the correct answer (without declaring that it is correct), to motivate their choice (phase 2). In this way, the students are led to focus on the justifications to the given answers and, then, could become more aware of the strategies they applied to solve the task (FA strategy E). As a consequence, the solving strategies are shared and discussed within the class. The students, activated as instructional resources for their classmates ( FA strategy D), give feedback to each other ( FA strategy C). Another important focus of this phase of the discussion is the comparison between the different ways of solving the task, in order to highlight the most efficient one and to give feedback about the processing of the task. This kind of meta-level analysis is carried out to make students become aware of the most effective ways of facing specific tasks. In this way, feedback about self-regulation is provided and students could expand the "repertoire" of possible strategies to adopt when facing again similar problems.

During the phases 1 and 2 of the discussion, some groups who faced difficulties in choosing the answer are asked to share their doubts and difficulties with their classmates. In this way, misconceptions are elicited and, consequently, students could give and receive feedback. Moreover, it often happens that some pairs/groups declare that they changed their mind during the discussion. During these phases of the discussion it is important to enable these students to share the reasons why they changed their mind, in order to activate themselves as owners of their own learning ( $F A$ strategy E).

The structure of classroom discussions is different when the discussions refer to a poll in which there is not one correct answer (categories 3 and 4).

Example 2, which refers to a poll on metacognitive aspects (in this case, efficient strategies to address problems containing graphs), illustrates a typical way of initiating the discussion in the case of polls belonging to categories 3 and 4. The discussion is initiated with the analysis of the most chosen option in order to raise meta-level issues. The display of results makes some students revise their initial answer, thus, turning themselves as responsible of their own learning ( $F A$ strategy $E$ ), 
or intervene to justify their choice, acting as resources for their classmates (FA strategy $D)$. An example of this activation of $F A$ strategies $E$ and $D$ is in lines 12-15, when Luca expresses his idea $(F A$ strategy $E)$ and the researcher relaunches it, so as to involve also the other students in the reflection and to turn Luca into a resource for his peers $(F A$ strategy $D)$. During the discussion, the teacher and the researcher intervene to give feedback that moves the students' learning forward ( $F A$ strategy $C$ ).

Another way of initiating (or developing) this kind of discussion is to focus on the options that where not chosen by students and to ask them to explain why they did not choose other options. In this way, other meta-level issues could be faced because students are stimulated to reflect on the reasons why they preferred an option instead of another one.

The episode presented in example 2 represents also an example of instant activation of a poll. Other frequent cases when the instant poll is initiated are situations where, during a classroom discussion on a problem worksheet, some incorrect answers emerge and the teacher decides to check whether all the students are aware of the non-correctness of these answers. This use of the poll may be linked to Beatty and Gerace's (2009) instructional purpose of eliciting a misconception. In the case in which this kind of poll is activated, students are asked to express their agreement with the incorrect solution, or to choose between different solutions (this kind of polls belong to category 1 or 2); the results of the poll are displayed and the subsequent discussion is aimed at working together towards a shared correct answer. Students who express the incorrect idea receive feedback $(F A$ strategy $C)$ and are led to become responsible of their own learning ( $F A$ strategy $E)$; students who point out that the idea is not correct act also as resources for their classmates (FA strategy $D)$.

Data analysis confirms that the teacher plays a crucial role in structuring the classroom discussion starting from polls to foster the activation of FA strategies. We believe that the different structures that we described, besides contributing to a theoretical reflection on the way polls may foster formative assessment, may also serve as a basis for guiding teacher practice and could be exploited in terms of teacher education. To this regard, we remark that in our design experiments the researcher collaborated with the teachers in developing effective classroom discussion. Further research is needed on the ways of supporting the teachers' autonomous use of this kind of resources.

\section{Acknowledgment}

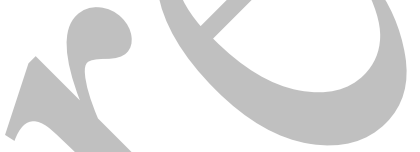

Research funded by the European Community's Seventh Framework Programme fp7/2007-2013 under grant agreement No [612337].

\section{REFERENCES}

Aldon, G., Cusi, A., Morselli, F., Panero, M., \& Sabena, C. (2017). Formative assessment and technology: reflections developed through the collaboration between teachers and researchers In G. Aldon, F. Hitt, L. Bazzini \& U. Gellert, Mathematics and technology: a CIEAEM source book. Series 'Advances in Mathematics Education'. Springer International Publishing.

Ares, N. (2008). Cultural practices in networked classroom learning environments. ComputerSupported Collaborative Learning, 3, 301-326.

Bartolini Bussi, M. G. (1998). Verbal interaction in mathematics classroom: A Vygotskian analysis. In H. Steinbring, M. G. Bartolini Bussi, \& A. Sierpinska (Eds.), Language and communication in mathematics classroom (pp. 65-84). Reston, VA: NCTM. 
Beatty, I.D, and Gerace, W.J. (2009). Technology-Enhanced Formative Assessment: A ResearchBased Pedagogy for Teaching Science with Classroom Response Technology. Journal of Science Education and Technology, 18, 146-162.

Black, P., and Wiliam, D. (2009). Developing the theory of formative assessment. Educational Assessment, Evaluation and Accountability, 21(1), 5-31.

Clark-Wilson, A. (2010). Emergent pedagogies and the changing role of the teacher in the TINspire Navigator-networked mathematics classroom. ZDM Mathematics Education, 42, 747761.

Collins, A., Brown, J.S., \& Newman, S.E. (1989). Cognitive Apprenticeship: Teaching the Crafts of Reading, Writing and Mathematics! In L.B. Resnick (Ed.), Knowing, Learning, and Instruction: Essays in Honor of Robert Glaser (pp. 453-494). Hillsdale, NJ: Lawrence Erlbaum Associates.

Cusi, A., Morselli, F. \& Sabena, C. (2017). Promoting formative assessment in a connected classroom environment: design and implementation of digital resources. Vol. 49(5), 755-767. ZDM Mathematics Education.

DBRC - The Design Based Research Collective (2003). Design-Based Research: An Emerging Paradigm for Educational Inquiry. Educational Researcher, 32(1), 5-8.

Hattie, J., \& Timperley, H. (2007). The power of feedback. Review of Educational Research, 77(1), 81-112.

Irving, K.I. (2006). The Impact of Educational Technology on Student Achievement: Assessment of and for Learning. Science Educator, 15(1), pp. 13-20.

Roschelle, J., \& Pea, R. (2002). A walk on the WILD side. How wireless handhelds may change computer-supported collaborative learning. International Journal of Cognition and Technology, $1(1), 145-168$.

Schoenfeld, A. H. (1992). Learning to think mathematically: Problem solving, metacognition, and sense-making in mathematics. In D. Grouws (Ed.), Handbook for research on mathematics teaching and learning (pp. 334-370). New York: Macmillan.

Vygotsky, L. S. (1978). Mind in society: The development of higher mental processes. Cambridge, MA: Harvard University Press.

Wiliam, D., \& Thompson, M. (2007). Integrating assessment with instruction: What will it take to make it work? In C. A. Dwyer (Ed.), The future of assessment: Shaping teaching and learning (pp. 53-82). Mahwah, NJ: Erlbaum. 